Tropical Journal of Pharmaceutical Research April 2010; 9 (2): 149-156

(C) Pharmacotherapy Group,

Faculty of Pharmacy, University of Benin,

Benin City, 300001 Nigeria.

All rights reserved.

Research Article

Available online at http://www.tjpr.org

\title{
Effect of Ethanol Extract of Indigofera tinctoria Linn (Fabaceae) on Lithium/Pilocarpine-Induced Status Epilepticus and Oxidative Stress in Wistar Rats
}

\author{
G Asuntha $^{1^{*}}, \mathrm{Y}$ Prasannaraju ${ }^{2}$ and KVSRG Prasad ${ }^{3}$ \\ ${ }^{1}$ Department of Pharmacy, S P W Polytechnic, Tirupati-517 502, India, ${ }^{2}$ Faculty of Pharmaceutical Sciences, UCSI \\ University, \#1, Menara Gading, UCSI Heights, 56000 Kuala Lumpur, Malaysia, ${ }^{3}$ Institute of Pharmaceutical \\ Technology, Sri Padmavati Mahila Visvavidyalayam (A Women's University), Tirupati-517 502, India.
}

\begin{abstract}
Purpose: Indigofera tinctoria Linn. of the Fabaceae family is claimed to be useful in the treatment of a variety of epileptic disorders in Indian traditional system of medicine. The present study was designed to verify this claim.

Methods: Status epilepticus was induced in male albino rats of Wistar strain by administration of pilocarpine (30 mg/kg, i.p.) $24 \mathrm{~h}$ after injection of lithium chloride (3 $\mathrm{mEq} / \mathrm{kg}$, i.p.). Different doses of the ethanol extract of Indigofera tinctoria were administered orally $1 \mathrm{~h}$ before the injection of pilocarpine. The severity of status epilepticus was observed and recorded every 15 min for 90 min and thereafter every 30 min for another 90 min, using Racine scoring system. In-vivo lipid peroxidation of rat brain tissue was measured in terms of the thiobarbiturate-reactive substances (TBARS). Both in-vitro free radical nitric oxide (NO) and 2-diphenyl-2-picryl hydrazyl (DPPH) scavenging activities of the extract were also determined.

Results: The severity of status epilepticus was significantly $(p<0.01)$ reduced following oral administration of the extract at 500 and $1000 \mathrm{mg} / \mathrm{kg}$ doses. No test animal group exhibited stage 4 seizure. The extract also exhibited both in-vivo and in-vitro antioxidant activities. .

Conclusion: The ethanol extract of Indigofera tinctoria was found to be useful in controlling lithium/pilocarpine-induced status epilepticus in albino rats.
\end{abstract}

Keywords: Indigofera tinctoria, Free radical scavenging, Status epilepticus, Antioxidant, Albino rats, Polyphenols. 


\section{INTRODUCTION}

Convulsive status epilepticus is a neurological emergency associated with high morbidity and mortality. It is defined as a condition in which there is either more than 30 min of continuous seizure activity, or two or more sequential seizures without recovery of full consciousness between the seizures [1]. Convulsive status epilepticus is one of the dysfunctions of the nervous system and up to $5 \%$ of the world population develops convulsions in their lifetime [2]. The principal causes of the condition are abrupt antiepileptic drug (AED) withdrawal or inappropriate switches of AED treatment, cerebrovascular disease, febrile illness, central nervous system (CNS) infections, CNS malignancy, metabolic disorders and drug toxicity. The first line of drugs in the management includes benzodiazepines, phenytoin and phenobarbital. Second line drugs include intravenous anaesthetics such as barbiturates, ketamine and propofol [3].

According to the World Health Organization, more than one billion people rely on plant and traditional medicines worldwide for the treatment of chronic ailments [4]. During the 1950s, there was a major development in clinical neuropharmacology and psychopharmacology when plant drugs such as Acorus calamus [5] and Convolvulus pluricaulis [6] were discovered for some CNS disorders such as epilepsy, psychosis, depression and anxiety [7]. Only a few drugs have been approved by regulatory authorities to treat multi-factorial ailments of the CNS. Natural products have played a significant role in the management of neuropsychiatric disorders. Medicinal plants such as Centella asiatica [8] and Withania somnifera [9] from India have been shown to possess activity by modern methods of neuropharmacology. Several plants used for the treatment of epilepsy in different systems of traditional medicine have shown activity when tested by modern bioassay methods, but many of such plants remain to be further investigated.
Increased oxidative stress has a role in the pathogenesis of coronary heart disease, neurodegenerative diseases, arthritis, epilepsy, cataract formation and immune system dysregulation. Enzymes and other small molecular antioxidants can protect experimental animals from the harmful effects of free radicals. The level of oxidative stress is used to identify an animal at risk for the development of the disease, or to monitor therapies directed at the disease. An increase in lipid peroxidation and excessive free radical formation occur during status epilepticus induced by pilocarpine [10].

Pilocarpine-induced status epilepticus model has provided information on the behavioral and neurochemical characteristics associated with seizure activity. The model has demonstrated permanent changes in different biochemical systems during status epilepticus [11]. Despite the availability of a large number of antiepileptics, current treatment is far from satisfactory. Approximately $30 \%$ of patients continue to have seizures with current antiepileptic drug therapy [12]. Thus, there is a need to evaluate newer, more effective and safer agents for the treatment of epilepsy. Medicines of plant origin are relatively non-toxic, safe and easily available at lower costs. Indigofera tinctoria, of the Fabaceae family, is claimed to be an antiepileptic according to the Indian indigenous system of medicine. The plant is used extensively by Indian practitioners of traditional medicine in the control of epilepsy. Systematic pharmacological studies have not been carried out to support its use. The present study was, therefore, carried out to evaluate the plant's effect on status epilepticus and oxidative stress.

\section{EXPERIMENTAL}

\section{Plant material}

The whole plant of Indigofera tinctoria was collected locally near Srinivasa Mangapuram area, Tirupati, Chittoor District, Andhra Pradesh, India in the month of June-July 
according to its seasonal availability. The plant was authenticated by Professor $T$ Vedavathi of the Department of Botany, Sri Venkateswara Arts and Science College, Tirupati, India. A voucher specimen was deposited at the herbarium of the Institute of Pharmaceutical Technology, A Women's University, Tirupati, India (ref. no.: 02/IT/08IPT-SPMVV/TPT/2004).

\section{Drugs and chemicals}

Pentylenetetrazole (PTZ), pilocarpine nitrate and artificial cerebrospinal fluid (ACSF) were purchased from Sigma-Aldrich, USA. Lithium chloride, HPLC grade chemicals and solvents of analytical grade were purchased from SD Fine Chem, Mumbai, India. Diazepam was obtained from Ranbaxy, New Delhi, India.

\section{Plant extract}

The plant material was shade-dried at room temperature in the laboratory, powdered and passed through a $250 \mu$ aperture sieve. A quantity $(200 \mathrm{~g})$ of the plant powder was extracted with $1000 \mathrm{ml}$ of $95 \%$ ethanol under reflux by heating over a water bath. The extracts were then vacuum-dried. The yield of the extract was $28.2 \%$. Suspensions of the extract were prepared with $2 \%$ Tween 80 before administration to animals.

\section{Experimental animals}

Male albino rats of Wistar strain weighing 150 $-200 \mathrm{~g}$ were used for the study. They were housed in polypropylene cages and maintained under standard laboratory conditions with a 12-12 h light-dark cycle and as well as free access to standard rat pellet diet (Lipton, India Ltd.) and drinking water. They were acclimatized to laboratory conditions for 10 days before starting the experiment. The experimental protocol was approved by the institutional animal ethical committee (ref. no: 1220/a/08/CPCSEA).

\section{Acute toxicity and gross behavioral changes}

The extract used in this study was subjected to acute toxicity studies. The rats were fasted overnight with free access to drinking water and divided into six groups, each containing six animals. Group 1 animals served as control and received distilled water orally (2 $\mathrm{ml} / \mathrm{kg}$ ). Animals in Groups 2 to 6 received $0.25,0.5,1.0,2.0$ and $4.0 \mathrm{~g} / \mathrm{kg}$, respectively, of the extract orally by gastric intubation using a soft rubber catheter. The animals were observed continuously for $2 \mathrm{~h}$ and then intermittently at one-hourly interval until 24th hour, their behavioural, neurological and autonomic profiles were noted. The animals were observed for mortality up to the 48th hour.

\section{Induction of Status epilepticus}

Thirty rats were divided randomly into 5 groups $(n=6)$. Group 1 animals (control) were administered distilled water $(2.0 \mathrm{ml} / \mathrm{kg}$, oral). Group 2 animals (reference standard) were treated with diazepam $(2.0 \mathrm{mg} / \mathrm{kg}$, i.p.) while Groups $3-5$ animals were administered 250, 500 and $1000 \mathrm{mg} / \mathrm{kg}$ orally of the extract, respectively. Twenty four hours prior to treatment, all the rats received lithium chloride (3 $\mathrm{mEq} / \mathrm{kg}$, i.p.). One hour after treatment, status epilepticus was induced to all the animals (including control group) by administering pilocarpine (30 $\mathrm{mg} / \mathrm{kg}$, i.p.). The severity of status epilepticus was observed and recorded every 15 min until the 90th $\mathrm{min}$ and thereafter every $30 \mathrm{~min}$ until 180th min, using Racine [13] scoring system: 0 (no response); 1 (fictive scratching); 2 (tremors); 3 (head nodding); 4 (forelimb clonus) and 5 (rearing and fall back).

\section{Effect of extract on brain lipid peroxidation}

Five groups were used $(n=6)$. Group 1 animals (control) were administered distilled water $(2.0 \mathrm{ml} / \mathrm{kg}$, oral) while Group 2 animals were administered Pentylenetetrazole (PTZ, 
$70 \mathrm{mg} / \mathrm{kg}$ ) subcutaneously as the reference standard. Groups $3-5$ animals were administered 250,500 and $1000 \mathrm{mg} / \mathrm{kg}$ of the extract orally. One hour after administration of the extract, PTZ $(70 \mathrm{mg} / \mathrm{kg}$ ) was injected subcutaneously to all the animals in Groups 3 - 5 animals. On observing onset of convulsions following the administration of PTZ, the animals (including control group) were sacrificed by decapitation. The brains were removed and immediately submerged in ice-cold artificial cerebrospinal fluid (ACSF). The tissues were then washed to remove blood, blotted with cotton wool to remove excess water and submerged in $5 \mathrm{ml}$ of methanol. It was then homogenized using a glass Teflon homogenizer for $2 \mathrm{~min}$ and centrifuged at $10,000 \mathrm{rpm}$ at $-10{ }^{\circ} \mathrm{C}$ for 15 min. The supernatant was assayed based on the reaction between malondialdehyde (MDA) and thiobarbituric acid (TBA). To a 10 $\mathrm{ml}$ volumetric flask, $0.5 \mathrm{ml}$ of supernatant of brain homogenate and $2.5 \mathrm{ml}$ of TCA were added and kept aside. Fifteen minutes later, $1.5 \mathrm{ml}$ of TCA and $3 \mathrm{ml}$ of TBA were added to the flask and then placed over a water bath for $30 \mathrm{~min}$. The flask contents were shaken for $5 \mathrm{~min}$ and centrifuged at $2000 \mathrm{rpm}$ for 15 min. The optical density of the supernatant was read at $532 \mathrm{~nm}$ against a blank (i.e., reaction mixture without brain tissue fluid) in a Shimadzu UV3600 spectrophotometer. Lipid peroxidation levels were expressed as ' $n$ ' moles of MDA formed/g of brain tissue which was computed from MDA standard curve.

\section{Determination of in-vitro scavenging of nitric oxide (NO)}

Nitric oxide (NO), generated as a result of decomposition of sodium nitroprusside in an aqueous medium, interacts with oxygen at physiological $\mathrm{pH}$ to produce nitrite ions, which are measured by using Griess reagent. The absorbance of the chromophore formed during the diazotization of nitrite with sulphanilamide and subsequent coupling with $\mathrm{N}$-napthylethylenediamine was read at 546 $\mathrm{nm}$ and referred to the absorbance of standard solution of potassium nitrite, treated the same way with Griess reagent. Clear solutions of the extract $(0.1,0.2,0.4,0.8$ and $1 \mu \mathrm{g} / \mathrm{ml}$ ) were prepared. One millilitre of sodium nitroprusside $(10 \mu \mathrm{M} / \mathrm{L})$ in $\mathrm{pH} 7.7$ phosphate buffer was added to each tube containing the extract. The mixtures were incubated at $25^{\circ} \mathrm{C}$ for $2 \mathrm{~h}$. An aliquot of 0.5 $\mathrm{ml}$ of the incubation solution was diluted with $0.5 \mathrm{ml}$ of Griess reagent. Absorbance was measured spectrophotometrically at $546 \mathrm{~nm}$. Ascorbic acid was used as a positive control.

\section{Determination of free radical 2-diphenyl-2- picryl hydrazyl (DPPH) scanvenging activity of extract}

This assay is based on the measurement of the scavenging ability of a test substance against the stable radical. The free radical scavenging activity of the extract was examined in-vitro using DPPH radical. Different concentrations of the extract $(0.1$ $1 \mu \mathrm{g} / \mathrm{ml}$ were added to $100 \mu \mathrm{g} \mathrm{DPPH} / \mathrm{ml}$ of ethanol and the tubes were maintained at ambient temperature for $20 \mathrm{~min}$ and the absorbance was measured spectrophotometrically at $517 \mathrm{~nm}$. Ascorbic acid was used as a positive control.

\section{Statistical analysis}

The data were expressed as mean \pm S.E.M. Statistica (StatSoft Inc.) version 6.0 was used to analyze the data. ANOVA was used for multiple comparisons followed by TukeyKrammer test. In addition lithium-pilocarpineinduced seizures were analyzed using Kruskal-Wallis ANOVA followed by Dunnet's test. $\mathrm{P}<0.05$ was considered statistically significant.

\section{RESULTS}

\section{Acute toxicity and gross behavioural changes}

The extract of $I$. tinctoria did not provoke any gross behavioral changes or manifestations of toxic symptoms in the animals such as 
weight loss, increased motor activity, tremors, clonic convulsions, tonic extensions, muscle spasm, spasticity, loss of right reflex, decreased motor activity, ataxia, sedation, muscle relaxation, hypnosis, arching and rolling, lacrimation, salivation, viscid, watery diarrheoa, writhing and urination over a period of $24 \mathrm{~h}$. Ethanolic extract of I. tinctoria was nonlethal even at the maximum single oral dose of $4.0 \mathrm{~g} / \mathrm{kg}$. Hence, the oral doses of the extracts selected for the study were 250,500 and $1000 \mathrm{mg} / \mathrm{kg}$.

\section{Effect of extract on lithium-pilocarpine induced Status epilepticus}

The results of the anti-epileptic activity of the extract are shown in Table 1. All the animals in the control group exhibited stage 4 seizures within $45 \mathrm{~min}$ after pilocarpine injection. Group 2 animals pre-medicated with the reference standard drug (diazepam) did not demonstrate stage 2 seizures or beyond. The extract was able to diminish the intensity of seizures in all test groups of animals and none of the animals exhibited stage 4 seizures. In the extract-treated animals, a significant $(p<0.01, p<0.001)$ reduction in the severity of lithium-pilocarpine induced status epilepticus was observed at oral doses of 500 and $1000 \mathrm{mg} / \mathrm{kg}$, respectively. The animals were almost normal in behavior after $180 \mathrm{~min}$.

\section{Effect of extract on brain lipid peroxidation}

The results for brain lipid peroxidation are presented in Table 2. The extract showed significant $(p<0.001)$ dose-dependent decrease in malondialdehyde (MDA) content in the test group animals of $9.2,13.8$ and $18.4 \%$ at oral doses of 250, 500 and 1000 $\mathrm{mg} / \mathrm{kg}$, respectively when compared to the control group.

\section{In-vitro antioxidant activity}

The results of the antioxidant activity of the extract against NO and DPPH are expressed in Table 3. The extract exhibited a significant $(p<0.001)$ concentration-dependent in-vitro

Table 1: Effect of the extract of I. tinctoria on lithium-pilocarpine-induced Status epilepticus

\begin{tabular}{|c|c|c|c|c|c|}
\hline & & & SCORE & & \\
\hline $\begin{array}{l}\text { Time after } \\
\text { pilocarpine } \\
\text { (min) }\end{array}$ & $\begin{array}{c}\text { Group 1 } \\
\text { Vehicle } \\
\text { (2 ml/kg/p.o.) }\end{array}$ & $\begin{array}{c}\text { Group } 2 \\
\text { Diazepam } \\
\text { (2 mg/kg/i.p.) }\end{array}$ & $\begin{array}{c}\text { Group } 3 \\
(250 \mathrm{mg} / \mathrm{kg})\end{array}$ & $\begin{array}{c}\text { Group } 4 \\
(500 \mathrm{mg} / \mathrm{kg})\end{array}$ & $\begin{array}{c}\text { Group 5 } \\
(1000 \mathrm{mg} / \mathrm{kg})\end{array}$ \\
\hline 15 & $1.5 \pm 0.20$ & $0.50 \pm 0.45$ & $1.40 \pm 0.45$ & $0.00 \pm 0.00^{*}$ & $0.00 \pm 0.00^{*}$ \\
\hline 30 & $3.00 \pm 0.49$ & $0.50 \pm 0.82^{\star *}$ & $2.00 \pm 0.30$ & $1.00 \pm 0.20^{*}$ & $0.00 \pm 0.00^{*}$ \\
\hline 45 & $3.80 \pm 0.20$ & $0.70 \pm 0.20^{\star *}$ & $2.50 \pm 0.30$ & $1.00 \pm 0.10^{*}$ & $1.00 \pm 0.85^{*}$ \\
\hline 60 & $4.00 \pm 0.07$ & $1.00 \pm 0.30^{*}$ & $3.00 \pm 0.55$ & $2.10 \pm 0.10$ & $1.50 \pm 0.09^{*}$ \\
\hline 75 & $4.50 \pm 0.20$ & $1.00 \pm 0.40^{*}$ & $3.80 \pm 0.20$ & $2.00 \pm 0.20^{*}$ & $2.00 \pm 0.48^{*}$ \\
\hline 90 & $5.00 \pm 0.88$ & $1.50 \pm 0.22^{\star *}$ & $3.50 \pm 0.30$ & $2.00 \pm 0.10^{*}$ & $1.50 \pm 0.95^{*}$ \\
\hline 120 & $3.80 \pm 0.20$ & $1.00 \pm 0.21^{*}$ & $3.00 \pm 0.20$ & $2.00 \pm 0.20$ & $1.00 \pm 0.10^{*}$ \\
\hline 150 & $2.00 \pm 0.05$ & $0.50 \pm 0.32^{*}$ & $2.00 \pm 0.41$ & $1.30 \pm 0.10$ & $0.00 \pm 0.00^{*}$ \\
\hline 180 & $1.00 \pm 0.68$ & $0.20 \pm 0.11^{* *}$ & $1.00 \pm 0.39$ & $0.50 \pm 0.10$ & $0.00 \pm 0.00^{*}$ \\
\hline
\end{tabular}


Asuntha et al

Table 2: Effect of the extract of $I$. tinctoria on brain MDA content

\begin{tabular}{ccccc}
\hline Group & Treatment & $\begin{array}{c}\text { Dose } \\
(\mathbf{m g} / \mathbf{k g})\end{array}$ & $\begin{array}{c}\text { MDA } \\
(\boldsymbol{\mu M} / \mathbf{g} \text { of brain tissue) })\end{array}$ & $\begin{array}{c}\text { Decrease } \\
\text { in MDA } \\
(\%)\end{array}$ \\
\hline 1 & Control $(2 \mathrm{ml})$ & & $0.87 \pm 0.62$ & 0.00 \\
2 & $\mathrm{PTZ}$ & 70 & $1.82 \pm 0.24$ & -109.20 \\
3 & EEIT+PTZ & 250 & $0.79 \pm 0.53^{*}$ & 9.20 \\
4 & EEIT+PTZ & 500 & $0.75 \pm 0.64^{*}$ & 13.80 \\
5 & EEIT+PTZ & 1000 & $0.71 \pm 0.53^{*}$ & 18.40 \\
\hline \multicolumn{5}{r}{${ }^{*} p<0.001$, compared to control group }
\end{tabular}

Table 3: In-vitro free radical scavenging activity of the extract of $I$. tinctoria

\begin{tabular}{ccccc}
\hline \multirow{2}{*}{$\begin{array}{c}\text { Extract concentration } \\
(\mu \mathrm{g} / \mathrm{ml})\end{array}$} & \multicolumn{2}{c}{ NO levels $(\mu \mathrm{g} / \mathrm{ml})$} & \multicolumn{2}{c}{ DPPH levels $(\mu \mathrm{g} / \mathrm{ml})$} \\
\cline { 2 - 5 } & Ascorbic acid & Extract & Ascorbic acid & Extract \\
\hline 0.1 & $3.6 \pm 0.51$ & $14.24 \pm 1.64^{*}$ & $5.90 \pm 0.85$ & $5.71 \pm 0.74$ \\
0.2 & $12.7 \pm 1.02$ & $24.15 \pm 2.18^{\star}$ & $13.50 \pm 1.12$ & $11.72 \pm 1.16$ \\
0.4 & $30.8 \pm 4.01$ & $29.82 \pm 3.75^{*}$ & $29.51 \pm 3.24$ & $19.42 \pm 3.12^{*}$ \\
0.8 & $61.25 \pm 7.25$ & $37.10 \pm 3.56^{*}$ & $62.15 \pm 5.96$ & $37.68 \pm 4.49^{*}$ \\
1 & $75.1 \pm 9.36$ & $44.29 \pm 4.18^{*}$ & $78.12 \pm 8.23$ & $47.45 \pm 4.10^{*}$ \\
\hline
\end{tabular}

${ }^{*} p<0.001$, compared to ascorbic acid

antioxidant activity against $\mathrm{NO}$ scavenging at all $(0.1-1 \mu \mathrm{g} / \mathrm{ml})$ test concentrations when compared with antioxidant activity of ascorbic acid, a positive control. The ethanolic extract of Indigofera tinctoria did not show significant in-vitro antioxidant activity against stable free radical 2-diphenyl-2-picryl hydrazyl (DPPH) scavenging at 0.1 and $0.2 \mu \mathrm{g} / \mathrm{ml}$ concentrations, but it has demonstrated a significant $\quad(p<0.001) \quad$ in-vitro antioxidant activity against DPPH at concentrations, 0.4, 0.8 and $1 \mu \mathrm{g} / \mathrm{ml}$ when compared to ascorbic acid antioxidant activity.

\section{DISCUSSION}

Epilepsy is a common chronic neurological disorder which imposes a burden on health care systems. It is a manifestation of a variety of diseases with variable mortality. Deaths could be due to the causative etiology itself, such as tumours, degenerative conditions or cerebrovascular diseases. Evidence indicates that the imbalance between excitatory and inhibitory neurotransmission in the brain is the main cause or seizure development in both experimental and clinical situations [14]. Pilocarpine-induced seizures, is one of the most frequently used model for temporal lobe epilepsy. In this model, lithium does not have proconvulsant effect in animals. However, animals pretreated with lithium have limbic seizures, following subconvulsant doses of pilocarpine. The combined effect of lithiumpilocarpine results in the accumulation of acetylcholine, inositol monophosphate and reduction in cortical inositol - about ten times greater than the effects obtained with either drug alone [15]. Our study revealed that the ethanol extract of $I$. tinctoria exhibited dosedependent reduction in the severity of lithiumpilocarpine induced status epilepticus. Lithium-pilocarpine induced status epilepticus correlates with both electrophysiological and neuropathological characteristics of temporal lobe epilepsy [16]. Hence, active principles from this plant may be useful in temporal lobe epilepsy. 
Oxidative stress in the central nervous system has been shown in several rodent models of experimental epilepsy such as the PTZ-induced seizures model [17]. PTZ may also trigger a variety of biochemical processes including the activation of membrane phospholipases, proteases and nucleases. Alteration in the membrane phospholipid metabolism results in liberation of free fatty acids, diacylglycerols, eicosanoids, lipid peroxides and free radicals [18]. The extract of $I$. tinctoria exhibited significant free radical scavenging activity against $\mathrm{NO}$ and DPPH and also reduced the levels of brain MDA.

Medicinal herbs with antioxidants are useful in diseases in which free radicals are involved, such as anoxia, ischemia of brain and epileptic neuronal damage, arteriosclerosis, rheumatic disorders and cancer $[19,20]$. Several studies on medicinal plants with free radical scavenging and antioxidant activities indicate that these activities are due to the presence of polyphenols and flavonoids [21]. Earlier chemical studies indicate the presence of phenolic compounds and flavonoids in $I$. tinctoria [22]. Hence, the antioxidant and free radical scavenging activities of the plant may be due to the presence of these compounds which are known to exert antioxidant effects.

Status epilepticus and oxidative stress are thought to be closely interrelated [23]. In the present study, lipid peroxidation and nitrite levels increased after status epilepticus. Lipid peroxidation is an index of irreversible neuronal damage of cell membrane phospholipid and has been suggested as a possible mechanism of epileptic activity [24]. A steady-state balance between the production of nitric oxide and metabolites and their destruction by antioxidant systems is present at normal conditions. The results of the present study show an increase in nitrite formation after status epilepticus, suggesting that there is a possible increase in concentrations of reactive oxygen species (ROS), which are often involved in neuronal damage. Pilocarpine induces status epilepticus, which can produce alterations in superoxide activity in different areas, thereby causing neuronal damage. Pilocarpineinduced status epilepticus produces several changes in variables related to the generation and elimination of oxygen free radicals in adult rats [25]. In addition, in the normal physiological state, changes in neuronal activity are accompanied by alterations in the metabolic rate, which induce modifications in cerebral blood flow. In pathological states, changes in the blood flow may not occur in the same way. There is clinical and experimental evidence of reduced oxygen availability after status epilepticus. Evidence for the role of free radicals in status epilepticus is based on the use of enzymatic and non-enzymatic antioxidant treatment for protection against seizures and for status epilepticus -induced neuronal damage [26].

\section{CONCLUSION}

Results based on the lithium-pliocarpine induced status epilepticus rat model demonstrated that the ethanol extract of Indigofera tinctoria is effective in reducing the severity of status epilepticus. This, therefore, supports the traditional use of the plant in the treatment of epilepsy. The extract also possesses both in-vitro and in-vivo antioxidant activities. Further studies are required to isolate the compounds responsible for the extract's activities and as well as establish its mode of action.

\section{REFERENCES}

1. Kameshwar P, Pudukode RK, Khaldoon Al-Roomi, Reginald $S$. Anticonvulsant therapy for status epilepticus. Br J Clin Pharmacol, 2007; 63(6): 640-647.

2. Sander JWAS, Shrovan SD. Epidermiology of the epilepsies. J. Neurol Neurosurg Psychiatry, 1996; 61:433-443.

3. Pitt-Miller PL, Elcock BJ, Maharaj $M$. The management of status epilepticus with a continuous propofol infusion. Anesth Analg, 1994; 78: 1193-1194. 
4. Silvers Karen, Taptiklis Emmaline LR. Herbal Foods: Are they efficacious and safe? Nutrition Today, 2005; 40: 13-16.

5. Dandiya PC, Chopra YM. CNS acting drugs from plants indigenous to India. Ind. J. Pharmacol, 1970; 2: 67-90.

6. Singh $R H$, Mehta AK. Studies on psychotropic effect of Medhya Rasayana drug: Sankhpushpi, Part I (Clinical Studies). J Res Ind Med Yog Homeo, 1977; 12: 18-25.

7. Duman RS, Heminger GR, Nestler ER. Molecular psychiatry. Adaptations of Receptor - coupled signal transduction pathways underlying stress - and drug-induced neural plasticity. J Nervous and Mental Diseas, 1994; 182: 692-700.

8. Abhang RY. A study to evaluate the effect of a micro (Sukshma) medicine from a Madhya Rasayana on intelligence of mentally retarded children using psychological and biochemical parameters. J Res Ayur Siddha, 1992; 13: 35-47.

9. Thatte $U$, Pandit SA, Shah LP. Ashwagandha (Withania Somnifera). Arch Ind Psychiat, 1995; 2: 53-55.

10. Simonie A, Laginja J, Varljen J, Zupan G, Erakovie $V$. Lithium plus pilocarpine induced status epilepticus: biochemical changes. Neurosci Res, 2000; 36: 157-166.

11. David Murdoch. Mechanisms of status epilepticus: an evidence-based review. Curr Opini Neurol, 2007; 20: 213-216.

12. Holmes GL. Critical issues in the treatment of epilepsy. Am J Hosp Pharm, 1993; 50: 85-116.

13. Racine RJ. Modification of seizure activity by electrical stimulation. II. Motor seizure. Electroencephalogr Clin Neurophysiol, 1972; 32: 281-294.

14. MacNamara JO. Cellular and molecular basis of epilepsy. J Neurosci, 1994; 14: 3413-3425.

15. Jope RS, Simonato $M$, Lally $K$. Acetylcholine content in rat brain elevated by status epilepticus induced by lithium and pilocarpine. J Neurochem, 1987; 49: 944-951.

16. Klitgaard H, Matagne A, Vanneste GJ, Margineanu DG. Pilocarpine-induced epileptogenesis in the rat: impact of initial duration of status epilepticus on electrophysiological and neuropathological alterations. Epileptic Res, 2002; 51: 93-107.

17. Rauca $C$, Zerbe $R$, Jantze $H$. Formation of free hydroxyl radicals after PTZ-induced seizure and kindling. Brain Res, 1999; 847: 347-351.

18. El-Tahir KE, Ashour MM, Al-Harbi MM. The cardiovascular actions of volatile oil of the black seeds (Nigella sativa) in guinea-pigs: elucidation of the mechanism(s) of action. General pharmacol, 1993; 24: 1123 -1131.

19. Houghton PJ, Zarka R, Dela Heras B, Hout JRS. Fixed oil of Nigella sativa and derived thymoquinone inhibit eicosanoid generation in leukocytes and membrane lipid peroxidation. Planta medica, 1995; 61: 33-36.

20. Medicana $R$, Janssens J, Tarasenko A. Antiangiogenic activity of Nigella sativa plant extract in cancer therapy, Proceedings: Annual meeting of the Am Assoc Cancer Res, 1997; 38: $A 1377$.

21. Lu Y, Foo LY. Antioxidant activities of polyphenols from sage (Salvia officinalis). Food Chem, 2001; 75:197-202.

22. Narender $T$, Khalid $T$, Anju Purib, Ramesh Chandra. Antidyslipidemic activity of furanoflavonoids isolated from indigofera tinctiria. Bioorg Med Chem Let, 2006; 16: 3411-3414.

23. MacNamara JO. Cellular and molecular basis of epilepsy. J Neurosci, 1994; 14: 3413-3425.

24. Atilla Ilhan, Arif Aladag M, Adbulkadir K, Ayhan B, Ahmet G, Ferah A. Erdosteine ameliorates $P T Z$-induced oxidative stress in mice seizure model. Brain Res Bul, 2005; 65: 495-499.

25. Dymond $A M$, Crandall $P H$. Oxygen availability and blood flow in the temporal lobes during spontaneous epileptic seizures in men. Brain Res, 1976; 102: 191-196.

26. Freitas RM, Silvania MMV, Francisca CFS, Glauce SBV, Marta MFF. Oxidative stress in the hippocampus after pilocarpine-induced status epilepticus in Wistar rats. FEBS Journal, 2005; 272: 1307-1312. 